Doi: http://dx.doi.org/10.5212/OlharProfr.v.12i2.257285

\title{
A QUALIDADE DE VIDA DOCENTE EM CURSOS DE LICENCIATURA ${ }^{1}$ \\ THE QUALITY OF LIFE OF PROFESSORS FROM UNDERGRADUATE PROGRAMS
}

\author{
Fernanda Pires BERTUOL* \\ Pura Lúcia Oliver MARTINS**
}

Resumo: O presente artigo tem como objetivo atentar para a qualidade de vida docente no Ensino Superior, em face da forte influência de determinadas condições histórico-culturais no processo de construção do mundo do trabalho, especialmente a partir da modernidade. Considerando que se realizam inúmeros estudos sobre a qualidade do ensino no Brasil, mas que ainda se dá pouca importância à qualidade de vida do professor, o texto apresenta resultados de uma pesquisa realizada em 2006, com 50 professores de licenciaturas de duas universidades de Curitiba-PR, uma pública e outra privada. Essa pesquisa possibilitou verificar aspectos comprometidos da qualidade de vida desses docentes e comprometedores em relação à sua prática pedagógica, já que a pessoa e o profissional são indissociáveis. Tal realidade evidencia condições de trabalho na área educacional adversas à qualidade de vida dos professores, decorrentes dos objetivos e modos de produção capitalistas. Por fim, indicam-se algumas possibilidades de superação dessa realidade.

Palavras-chave: Trabalho. Educação. Qualidade de Vida. Ensino Superior.

Abstract: This study attempts to measure the quality of life of university professors considering certain historical and cultural variables in the workplace that influence the construction process, especially after modernity. Whereas many studies

\footnotetext{
${ }^{1}$ Artigo baseado em dissertação de Mestrado apresentada em 2007 ao Programa de Pós-graduação em Educação, da PUCPR.

* Mestre em Educação pela PUC-PR. E-mail: fbertuol@yahoo.com.br.

${ }^{* *}$ Doutora em Educação pela USP. E-mail: pura.oliver@pucpr.br
} 
A qualidade de vida docente em cursos de licenciatura

consider the quality of education in Brazil, little importance is given to the quality of life of teachers. Therefore this study presents the results of a survey conducted in 2006, with 50 undergraduate teachers at a public university and other private schools, in Curitiba, PR. This study enabled us to verify aspects of the compromised quality of life of teachers that affects their teaching, since the person and work are inseparable. Such reality shows work conditions in education adverse to quality of life of teachers, resulting from the goals and modes of capitalist production. Finally, some possibilities to overcome this reality are suggested.

Keywords: Work. Education. Teaching. Quality of life. Higher Education.

\section{INTRODUÇÃO}

A atenção à realidade em que se instaura a qualidade de vida do professor, sob condições de trabalho adversas na Educação, considerando-se sua relação dialética com a própria prática pedagógica, é emergente e imprescindível na contemporaneidade.

Com esse enfoque, o presente artigo aborda determinados aspectos históricos e socioculturais do mundo do trabalho, ocorridos no final do século XX, e discute os seus impactos na Educação e no trabalho docente, ressaltando a supervalorização da objetividade, da mensuração e do controle, em detrimento da subjetividade, com base nos modos de produção norte-americanos.

Em seguida, são analisados esses impactos diretamente na qualidade de vida do professor, destacando-se a prática docente em cursos de licenciatura, em vista das particularidades do seu papel social. São apontados, então, os problemas decorrentes das condições do trabalho docente, os quais tanto afetam a saúde do professor quanto atingem a sua prática pedagógica. Assim, a forte relação existente entre trabalho, saúde e educação é evidenciada mediante a complexidade da qualidade de vida, sendo esta compreendida como "a cultura adotada ou construída por uma pessoa, que orienta sua prática de ser em relação à sua saúde". (BERTUOL, 2006, p. 27).

Com o intuito de compartilhar aspectos dessa realidade docente, é apresentado um estudo sobre a qualidade de vida de professores 
de licenciaturas, cujos resultados indicam uma aparente polaridade entre trabalho e qualidade de vida, na própria prática do trabalho. Tal fato exige muito tempo e dedicação do professor, descompensando os outros aspectos da sua vida particular, que requerem tempo livre. $\mathrm{E}$ esse desequilíbrio acaba comprometendo a sua qualidade de vida em alguns âmbitos em especial e ameaçando a própria prática docente.

Nesse quadro, algumas medidas são identificadas e apontadas, envolvendo o professor enquanto sujeito concreto e ativo nesse processo, bem como diferentes instâncias sociais, de forma a ampliar o presente debate.

\section{ASPECTOS HISTÓRICOS E SOCIOCULTURAIS DO TRABALHO E SEUS IMPACTOS NA EDUCAÇÃO}

O século XX, após a industrialização, foi considerado um período de progressos técnicos e científicos, mas, também, experimentou regressões. (MOREIRA, 2001). O novo modelo de produção massificada e seriada no trabalho resultou em danos à vida dos trabalhadores, dentre os quais os professores universitários não foram exceção.

As mudanças resultantes desse avanço da modernidade foram impostas ao trabalhador. Por um lado, exigiram-lhe o desenvolvimento de determinadas aptidões, que aproximam o seu comportamento ao de uma máquina; e, por outro, mas não em sentido oposto, suprimiram algumas de suas habilidades e capacidades, tais como: a integração, a interação, a criatividade, a comunicação, a reflexão, o relacionamento interpessoal, a solução de problemas, o autoconhecimento e a autoestima.

Em prol de maior acumulação de capital pelos proprietários das fábricas, essas mudanças foram fundamentadas nos modelos norte-americanos da Administração de Sistemas, que se apoiou na Teoria Geral dos Sistemas, criada nos anos 30 pelo biólogo Ludwig Von Bertalanffy. Essa teoria pretendia responder à complexidade dos organismos vivos, valorizando seus princípios comuns e sendo aplicável à realidade empírica. Assim, na década de 60 , ela foi adaptada à administração, considerando-se que cada organização vive e opera num ambiente do qual capta materiais, informações, energia, e ao qual oferta e vende seus produtos, demonstrando sua preocupação com a demanda e a produtividade, em uma abordagem contingencial. (CHIAVENATO, 1993). Contudo, um dos problemas dessa fusão 
A qualidade de vida docente em cursos de licenciatura

foi compreender os sitemas sociais como equivalentes aos sistemas naturais, tendo a causalidade como seu denominador comum: para a maior acumulação de capital (efeito) é necessária uma maior produtividade (causa), cuja capacidade está no trabalho operacional, mecanizado, massificado e seriado. Ressalta-se que essa maneira de pensar a administração estava atrelada à tentativa de se consolidar, estabelecer, controlar e garantir, ideologicamente, princípios comuns entre as formas de produção do trabalho e os objetivos capitalistas.

Os modos de produção fundamentaram-se em uma concepção materialista e mecanicista que supervaloriza a objetividade, a mensuração e o controle, em detrimento da subjetividade, sendo esta o "conjunto de condições que torna possível que instâncias individuantes e/ou coletivas estejam em posição de emergir como território existencial auto-referencial em adjacência ou em relação com uma alteridade a ela mesma subjetiva". (GUATTARI, 1993, p. 19). Contendo um potencial demasiadamente comunicativo e sendo instaurada sobre um plano abstrato, a subjetiviade é repleta de signos, símbolos e significados que requerem processos mais demorados e incertos de interpretação, dificultando assim o controle sobre a sua realização e repercussão e ameaçando a almejada "ordem" para a maior produtividade possível.

Em decorrência desse processo, um dos principais problemas que surgiram nessa época foi o utilitarismo concernente ao próprio corpo humano.

O desenvolvimento industrial acabou por industrializar também as percepções e anseios humanos, adequando-os aos seus princípios de produção e sustentação. Como esse processo industrial determinou uma forma de trabalho e, portanto, uma forma de organização social, todo um sistema cultural passa a desenvolver-se a partir de então. A cultura que aí viceja passa a ser resultante de um pragmatismo em que a utilidade se impõe como a intenção primeira das aspirações e ações humanas. O próprio corpo instrumentaliza-se como propriedade utilitária e se objetifica num processo de troca. A sociedade começa então a se caracterizar como uma sociedade de objetos. (ZUIN, 1999, p. 160).

Além da rapidez dos avanços ter dificultado seu acompanhamento pela sociedade, os modelos nos quais se estabeleceram no mundo do trabalho foram ainda mais determinantes à negação 
humana de "adaptação" a essa realidade. Não foi possível e nem desejado aprender a conviver com as condições objetivas e mecanicistas resultantes da industrialização, uma vez que, arbitrariamente, elas excluíram a subjetividade do trabalhador, imprescindível não somente à sua aprendizagem e adaptação a mudanças, mas também ao seu real envolvimento em situações cujas habilidades e capacidades são as mesmas que lhe foram suprimidas. É importante lembrar que essas habilidades e capacidades dependem diretamente da saúde e da liberdade de ser do trabalhador.

Com o progresso, foram estabelecidos condicionantes culturais. O dualismo entre corpo e mente, emoção e razão, subjetividade e objetividade, que fragmentou o ser em prol da ordem para maior produtividade, consolidou formas superficiais de ação e interação dos sujeitos. O trabalho realizado sob as condições de uma estrutura fragmentada e dicotômica, em vez de dignificar o homem, promovendo sua realização e socialização, priva-o da liberdade, da criatividade, da sociabilidade, da humanidade, da felicidade e, por fim, da própria vitalidade. Assim, "para os trabalhadores, a construção da saúde é a mobilização consciente ou não das potencialidades de adaptação do ser humano, permitindo-lhe interagir com o meio de trabalho e lutar contra o sofrimento, a morte, as deficiências, as doenças e a tristeza". (ASSUNÇÃO, 2003, p. 98).

No período que se inicia com a recuperação econômica pós-1930 e se estende até a crise da década de 1970, o processo produtivo e a organização do trabalho estão ainda sob a égide do taylorismofordismo. A economia de escala e a produção em série para o consumo de massa, implicam o uso de um grande contingente de trabalhadores, o que facilitava tanto a organização sindical como a regulamentação estatal. Assim, o chamado "Estado de Bem-Estar" traduziu um determinado grau de compromisso entre Estado, empresas e sindicatos de trabalhadores que, numa fase de crescimento da economia, assegurou um relativo equilíbrio social e impulsionou significativamente o desenvolvimento das forças produtivas capitalistas, cujo resultado se materializou num avanço tecnológico de tal proporção que deu origem a uma nova "revolução industrial": a revolução microeletrônica, também denominada "revolução da informática" ou "revolução da automação". (SAVIANI, 2002, p. 20-21). 
A qualidade de vida docente em cursos de licenciatura

Com as mudanças no mundo do trabalho, a concepção de ciência foi alterada conforme a valorização da técnica.

[...] nesse processo, a capacidade produtiva do trabalho humano inegavelmente atinge proporções ilimitadas. A produção automatiza-se, isto é, se torna autônoma, auto-regulável, o que permitiria liberar o homem para a esfera do não-trabalho, possibilitando o cultivo do espírito através das artes, das ciências, da filosofia e do desfrute do tempo livre. Entretanto, essas possibilidades são tolhidas pelas relações sociais vigentes que, fundamentadas na apropriação privada dos meios de produção, dificultam a generalização da produção baseada na incorporação maciça das tecnologias avançadas. Nessas condições o avanço tecnológico foi utilizado para alterar o padrão produtivo, introduzindo a acumulação flexível a qual substituiu o taylorismo-fordismo pelo toyotismo, com o que se deslocaram os mecanismos de controle para o interior das próprias empresas, secundarizando o papel dos sindicatos e do Estado. Assim, de premissa objetiva para a liberação geral da humanidade do jugo das necessidades materiais, o avanço tecnológico converte-se, sob as relações sociais de produção capitalista, em instrumento de maximização da exploração da força de trabalho, ampliando a marginalização social através do crescente desemprego mantido sob controle. (SAVIANI, 2002, p. 21).

O saber, que era contemplativo, passou a ser ativo e capaz de atuar sobre o mundo, transformando-o. A nova compreensão da ciência e da tecnologia dita regras mais severas à vida dos sujeitos, no momento em que a responsabilidade pela realização dos seus ditames incide sobre os diversos segmentos públicos e privados da sociedade, dos quais depende a sobrevivência dos cidadãos mediante o trabalho e a utilização dos serviços disponíveis.

No final da década de 60 do século XX, o Estado Revolucionário, em transição, deixava de se expressar na forma de Estado burguês e voltava a sua atenção ao desenvolvimento econômico com segurança, apoiando a inserção das multinacionais no Brasil. Segundo Antunes (2006, p. 31),

como resposta à sua própria crise, iniciou-se um processo de reorganização do capital e de seu sistema ideológico e político de dominação, cujos contornos mais evidentes foram o advento do 
neoliberalismo, com a privatização do Estado, a desregulamentação dos direitos do trabalho e a desmontagem dos setores produtivos estatal.

Nesse cenário, a Educação tornou-se o principal alvo de demandas da sociedade industrializada, sendo encarregada de formar mão-de-obra operária "suficientemente aculturada, de modo a poder operar máquinas mais sofisticadas e poder organizar o próprio trabalho de modo mais móvel e aberto". (CAMBI, 1999, p. 626). Porém, distante da possibilidade de atender às novas e crescentes exigências, o sistema escolar apresentava uma baixa produtividade diante da enorme demanda que se apresentava.

A propósito disso, Mello (1982, p. 28) ressalta:

[...] a baixa produtividade, expressa por baixos índices de satisfação da demanda escolar em relação ao total da população e pelos altos índices de evasão e repetência, era apresentada como um dos entraves ao atingimento daquele objetivo. Isto porque o produto inadequado do sistema escolar era apontado como responsável, por um lado, pela baixa qualificação de mão-de-obra, e, por outro, pelo despreparo das massas para o processo político.

Assim, o Estado, os representantes de interesses oficiais e os chamados 'intelectuais', isto é, os cidadãos com maior nível cultural, dentre os quais se destacaram os economistas da educação, combateram tais ineficiências com propostas de planejamento educacional. Eles não hesitaram em inserir na Educação, através da chamada "pedagogia tecnicista", os mecanismos americanos tayloristas-fordistas de objetivação do trabalho, vigentes nas fábricas. Em um segundo momento, iniciou-se a reforma universitária, com base no toyotismo, flexibilizando e diversificando as organizações educacionais e o trabalho pedagógico, o que tornou secundário o papel do Estado, passando-se a apelar pela benemerência e ao voluntariado. (SAVIANI, 2002).

A idéia de reforma devia partir do projeto de objetivar a nova cultura científica e tecnológica que temos de ministrar na universidade. Essa nova cultura é uma cultura operacional e altamente especializada, exigindo métodos de transmissão muito elaborados e precisos, em que as idéias não são apenas formas de compreen- 
A qualidade de vida docente em cursos de licenciatura

são e entendimento, mas planos e modos de ação, de prática, de operação. (TEIXEIRA, 1989, p. 133).

A tecnologização na Educação resultou de um processo de racionalização voltado à eficiência e eficácia do sistema de ensino, visando a superar suas dificuldades e garantir sua funcionalidade, no atendimento à crescente demanda social. Isso, de acordo com os ditames tayloristas, fordistas e toyotistas, deveria ocorrer em tudo o que se refere à organização do trabalho, seu controle e, consequentemente, à especificação de elementos do processo administrativo.

Com efeito, a Educação foi incumbida de adequar a sociedade aos parâmetros do mercantilismo liberal de individualidade, produtividade e competitividade, passando a ser vista como mediadora e facilitadora do progresso econômico, apoiada pelas determinações pragmáticas materialistas e mecanicistas que foram impostas ao processo pedagógico. A pedagogia tecnicista, vinculada à Teoria Geral dos Sistemas, de cunho funcionalista e positivista, foi sucumbida às leis naturais, não admitindo conflitos, apenas relações consensuais, já que seu foco voltou-se à racionalidade técnica, inclusive na compreensão do próprio homem sobre o mundo e sobre si mesmo.

A preocupação excessiva com o uso de recursos tecnológicos na didática, com os métodos visualizados como fins e não como meios, e a desconsideração da relação entre a Educação e a sociedade estão na base da pedagogia tecnicista, que teve forte repercussão no Ensino Superior, a partir da década de 70. Essa pedagogia reproduziu técnicas difusoras da cultura desinteressada e formadora de perfis profissionais padronizados para a segurança do equilíbrio do sistema, no qual os sujeitos não podiam participar conscientemente dos processos, pois se renegava a manifestação de contradições e reduziam-se as relações interpessoais na tentativa de se exterminar os erros humanos.

$\mathrm{Na}$ concepção tecnicista, a aprendizagem torna-se um instrumento promotor de modificações de comportamentos das massas para adequá-los às exigências sociais, políticas e econômicas do modelo em vigor, com a finalidade de torná-los possíveis de avaliação e controle, principalmente durante a execução de tarefas. Com isso, os professores, mais do que outros trabalhadores, foram diminuídos ao status de técnicos especializados dentro da burocracia escolar, cuja função restringiu-se a administrar e implementar programas curriculares, deixando à margem o desenvolvimento crítico de currículos realmente preocupados com os objetivos educacionais. (GIROUX, 1997). Disponível em <http://www.uepg.br/olhardeprofessor> 
Giroux (1997, p. 159) afirma que, no cerne de tal instrumentalismo e pragmatismo da vida escolar, colocam-se diversas suposições pedagógicas importantes, que incluem: "o apelo pela separação de concepção e execução; a padronização do conhecimento escolar com o interesse de administrá-lo e controlá-lo; e a desvalorização do trabalho crítico e intelectual de professores e estudantes pela primazia de considerações práticas".

A divergência entre algumas demandas sociais e a Educação e a dificuldade inerente ao professor, sujeito e ator social, ambas impostas pela atual condição humana de existência, são fortemente influenciadas pelo materialismo histórico, mais especificamente pelas formas das relações de trabalho, as quais representam condições de vida, assumindo uma função significativa na formação pessoal do professor.

Para Zuin (1999, p.196-197),

o trabalho (sem deixar de ser entendido como processo de autogeração humana e processo objetivo de existência da espécie) continua ocupando o lugar de figura central da teoria educacional dialética. Mas interpretá-lo como condição e realização do ser humano exige a associação da teoria do trabalho a uma teoria do indivíduo e do sujeito. Isto significa que o trabalho (prática social) deve deixar de ser uma condição determinante e unilateral e passar a ser estudado como um problema de uma dialética de objeto e sujeito. Por outro lado, a formação torna-se indissociável do sujeito. Discutir como um se estabelece exige a presença da outra, e vice-versa.

Na prática, não existe separação entre pessoa e profissional. Da mesma forma, a qualidade de vida é uma só, mesmo realizando-se em diferentes dimensões. É nesse sentido e frente ao seguinte paradoxo que a qualidade de vida docente requer maior atenção: de um lado, a necessidade de melhor qualidade de vida expressa pela sociedade demanda a intervenção de diferentes áreas e órgãos públicos e privados, dentre os quais está a Educação realizada nas instituições de ensino; de outro, a precariedade das condições de trabalho interfere na qualidade de vida do professor e, assim, na sua ação educativa. Isto é, exige-se que a ação pedagógica se volte à melhor qualidade de vida social, mas, arbitrariamente, o professor tem a mesma necessidade.

O professor, sujeito histórico e social, não excede aos referidos condicionantes. Pelo contrário, esse é duplamente seu foco, estando 
A qualidade de vida docente em cursos de licenciatura

no centro de exigências sociais características do mundo globalizado, enquanto cidadão comum e profissional responsável pela formação de outros sujeitos, conforme demandas sociais e do mercado. Essas demandas foram conjugadas entre as décadas de 1980 e 1990, quando "a Teoria do Capital Humano promoveu um deslocamento da ênfase na função da escola como âmbito de formação para o emprego". (GENTILI, 2002, p. 48).

A propósito, Cunha (1989, p. 24) enfatiza que

a escola é uma instituição contextualizada, isto é, sua realidade, seus valores, sua configuração variam segundo as condições histórico-sociais que a envolvem. (...) O professor com relação à escola é, ao mesmo tempo, determinante e determinado. Assim, como seu modo de agir e de ser, recebem influências do ambiente escolar, também influencia este mesmo ambiente. (...) Esse jogo de relações entre a escola e a sociedade precisa ser, cada vez mais, desvendado para que se possa compreender e interferir na prática pedagógica.

As duas faces desse paradoxo, que envolvem o aspecto pessoalsocial e o profissional-social, são dependentes entre si, pois o homem é indicotômico. Porém, suas possibilidades de ação estão presas às limitações de cada uma, ao passo que a possibilidade de superação desse paradoxo está no próprio professor, pois ele, enquanto um ser biopsicosocial integral, tanto luta pela sua saúde e liberdade, quanto deseja realizar-se realizando a educação, enquanto profissional consciente e motivado pelo seu papel social. "O trabalho humano, enquanto atividade consciente, não é de caráter causal, mas teleológico. Engendra, por isso, opção, escolha e liberdade". (GENTILI, 2002, p. 63).

\section{AS RELAÇÕES ENTRE A QUALIDADE DE VIDA DOCENTE E A PRÁTICA PEDAGÓGICA}

A realidade inscrita sobre a qualidade de vida e o papel social do trabalho do docente das Instituições de Ensino Superior é ainda mais enfatizada ao se pensar, especificamente, no trabalho dos professores dos cursos de licenciaturas, pois, além de serem responsáveis pela formação humana, eles são responsáveis pela formação de professores- 
formadores. Entretanto, as exigências e condições de trabalho desses professores configuram-se como agravantes à sua qualidade de vida, a qual, ao mesmo tempo, representa suas condições básicas para a realização do trabalho pedagógico.

Parte da responsabilidade pela qualidade de vida social cabe, simultânea e respectivamente, às instituições educacionais; ao corpo docente dessas instituições; à formação desses professores; especificamente, às instituições de Ensino Superior e, de modo especial, aos cursos de licenciaturas, dentre os quais se destacam os de Biologia, Filosofia, Pedagogia e Educação Física, cujos objetivos principais são voltados ao estudo da vida, do pensamento, da aprendizagem e à prevenção de doenças e promoção da qualidade de vida.

A pressão é ainda maior quando a complexidade dessas exigências aumenta. Além de ser o principal foco dessas exigências, o professor de licenciatura é responsabilizado pela formação de novos educadores. A ação pedagógica desse docente é sobrecarregada de uma diversidade de solicitações e atribuições: "A profissão de professor exige de seus profissionais alteração, flexibilidade, imprevisibilidade. Não há modelos ou experiências modelares a serem aplicadas." (PIMENTA; ANASTASIOU, 2002, p. 199). Em decorrência disso, no momento em que tantas exigências se fazem muito mais ao professor do que ao sistema de ensino, a sua qualidade de vida e a própria prática pedagógica padecem. Segundo Enguita (1989, p. 125),

No contexto da carreira obsessiva e do domínio geral do discurso da eficiência, as escolas, através de mais ilustres reformadores inspirados no mundo da empresa, importaram seus princípios e normas de organização de forma extremada em ocasiões delirantes, mas sempre com notáveis conseqüência para a vida nas salas de aula.

Com efeito, "assumir as novas funções que o contexto social exige dos professores supõe domínio de uma ampla série de habilidades pessoais que não podem ser reduzidas ao âmbito da cumulação do conhecimento". (ESTEVE, 1999, p. 38). O conhecimento não assegura ao professor saber lidar com a diversidade de situações que se apresentam no mundo da educação, somadas ao acúmulo de exigências de trabalho, pois, como qualquer ser humano, antes de tudo o professor luta pelo bem de sua vida. 
A qualidade de vida docente em cursos de licenciatura

Essas condições, enraizadas na cultura social vigente, são adversas principalmente à saúde do professor, sendo que seus condicionantes culturais se colocam, em grande escala, na própria realização do trabalho, assumindo formas exageradas de isolamento, flexibilidade, agilidade, adaptação, disciplina, constância e resistência. Segundo Limongi-França (2004, p. 32), os referidos condicionantes culturais se expressam em "inquietudes, individuais e coletivas, quanto a pressões, conciliação de expectativas entre trabalho, família e consumo, sinais de stress, hábitos alimentares e cuidados físicos, estilos de vida, impactos tecnológicos".

Então, um dos mesmos motivos que geram a educação danificada, gera a vida danificada: a dicotomia entre teoria e prática, mas em um sentido mais amplo, proveniente da fragmentação do homem em uma parte corpórea e outra psíquica, de cunho cartesiano. A associação entre vida e educação torna-se evidente porque tanto a ação pedagógica quanto a qualidade de vida docente encontram suas bases de realização uma na outra. A qualidade da ação pedagógica depende da qualidade de vida do professor, assim como a qualidade de vida do professor encontra nas condições e na qualidade da ação pedagógica suas possibilidades de ascenção ou declínio.

No entanto, o trabalho pedagógico está envolvido em todo um sistema educacional que, por sua vez, apresenta exigências arbitrárias às reais condições da pedagogia e aos próprios princípios da Educação, proporcionando, assim, em resposta, a reprodução de motivos que retroalimentam as mesmas exigências.

Assim, é pelo desvio entre as exigências implícitas do sistema de ensino e a realidade de seu público que se explicam tanto a função conservadora da pedagogia tradicional como não-pedagogia quanto os princípios de uma pedagogia explícita que pode ser objetivamente exigida pelo sistema sem entretanto se impor automaticamente na prática dos docentes porque ela exprime a contradição desse sistema e porque contradiz os seus princípios fundamentais. (BOURDIEU, 1982, p. 113).

Nessa perspectiva, tanto a qualidade da ação pedagógica quanto a qualidade de vida do professor estão submetidas às contradições do sistema de ensino. Entretanto, a solução desse dilema pode estar na própria compreensão de que essas contradições também se dão a partir da qualidade da ação pedagógica e da qualidade de vida docente. 
Ao entender-se que "são as experiências e as condições de vida que favorecem a formação dos conceitos e do desempenho do indivíduo" (CUNHA, 1989, p. 45), também é compreensível que a qualidade de vida do professor seja imprescindível à valorização e à qualificação da sua ação pedagógica, bem como ao seu potencial de intervenção e transformação nas/das circunstâncias de trabalho que se apresentam e o exigem como "bom professor".

No estudo de Cunha (1989), sobre o "bom professor e sua prática', alunos do Ensino Médio e Superior relacionam ao bom professor os seguintes fatores: condições básicas de conhecimento de sua matéria de ensino; habilidades para organizar suas salas e manter relações positivas com os alunos; a visão de mundo do professor e seu potencial em perceber, estimular e considerar a aprendizagem dos alunos durante sua atuação, despertando a curiosidade, orientando a pesquisa, favorecendo a análise crítica, demonstrando que gosta do que faz e tendo senso de humor. Os alunos valorizam o professor que tem o papel de orientador em estágios, projetos finais, monografias, dentre outros trabalhos e estudos.

Essas características do bom professor expressam as expectativas dos alunos para a otimização do próprio desempenho docente no processo de aprendizagem discente, o que requer a consideração, facilitação e promoção da expressão da afetividade, capacidade de reflexão, atenção, flexibilidade, adequação, motivação e criatividade, assegurando a proximidade e a pessoalidade na relação professoraluno. Ao mesmo tempo, essas habilidades são as próprias condições pessoais de vida do professor; contróem a sua cultura e são construídas por ela, designando hábitos, costumes, crenças, atitudes e posturas.

Com efeito, a qualidade de vida do professor de lincenciatura, compreendida como gênese e resultado de suas ações, dentre elas a pedagógica, define o seu potencial profissional em direção às capacidades biopsicosociais de contextualização, criação, adaptação, motivação, interação, intervenção, reflexão, orientação, convivência, socialização, atenção, concentração, comunicação, percepção, abstração, resistência física e relação, tão caras à ação docente.

A qualidade de vida, compreendida como a cultura pessoal construída socialmente nos diferentes meios onde o sujeito interage, é condição para o trabalho, mas é também condicionada às circunstâncias do trabalho, as quais, especialmente na docência em licencia- 
A qualidade de vida docente em cursos de licenciatura

turas, envolvem o ambiente físico, os recursos materiais e didáticos, as relações humanas, os objetivos e valores da educação, a filosofia e a gestão institucional, a estruturação curricular, os conteúdos disciplinares, o estudo e a produção do conhecimento, a remuneração, o reconhecimento do profissional pela instituição, a formação continuada, as atividades específicas realizadas (aulas, orientações, avaliações, pesquisa, extensão etc.), a diversidade sociocultural, a quantidade de alunos e, principalmente, a responsabilidade sobre a formação de novos educadores e a contrastante diferença entre o tempo dedicado ao trabalho e o tempo livre.

Nesse quadro de múltiplas exigências e condições limitadas, principalmente no que se refere ao tempo escasso,

[...] o trabalho do professor sofre alterações em sua forma de organização, seus objetivos e destinação sustentados pelas políticas educacionais vigentes. As implicações para a saúde do professor, diante das atuais formas de ser do trabalho educativo configuram um quadro problemático, que permeia desde o abandono da carreira até problemas de saúde, relacionado ao sofrimento, colocando em questão a relação entre a objetividade social, os sentidos do trabalho e a sua não realização. (LANDINI, 2007, p.1).

Sob essas condições, o trabalho acomete a qualidade de vida do professor e, na mesma proporção, o seu organismo responde a essas adversidades. Dejours (1989) verificou isso em seus estudos sobre o conflito entre organização do trabalho e funcionamento psíquico, concluindo que os trabalhadores não são passivos frente às exigências e pressões do trabalho. Mesmo sofrendo, buscam proteger-se dos efeitos nocivos à sua saúde mental, exercendo sua liberdade, ainda que de forma limitada, na criação de sistemas defensivos coletivos.

No entanto, como frequentemente as exigências superam suas possibilidades, o sofrimento dos professores está se tornando cada vez mais constante na atualidade. De acordo com Codo (2006), quanto maior a defasagem entre o trabalho objetivado e o trabalho realizado nas escolas, maior será a exigência de investimento afetivo e cognitivo ao professor, que realizará um maior esforço e aumentará, assim, o seu sofrimento no cotidiano do trabalho.

As condições do trabalho docente, que apontam a precariedade da saúde do professor, a qual, por sua vez, ameaça a própria prática educativa, têm na compreensão fragmentada da complexidade do 
homem e na desvalorização da subjetividade humana os seus maiores vilões. É em face desses dois problemas geradores que a valorização da qualidade de vida docente é de emergente importância, pois considera intrinsecamente tanto a subjetividade quanto a integridade e a complexidade humana.

Portanto, o estudo da qualidade de vida docente pode proporcionar o conhecimento da relação complexa entre fatores que constituem a qualidade de vida humana, bem como possibilitar a valorização dos aspectos humanos marginalizados culturalmente, os quais se refletem diretamente na prática pedagógica, assim como também são fruto das condições dessa prática. Esse foi o propósito da pesquisa apresentada a seguir, realizada em 2006 com professores universitários.

\section{ESTUDO SOBRE A QUALIDADE DE VIDA DE PROFESSORES DE LICENCIATURAS}

\section{METODOLOGIA}

Em oposição ao desenvolvimento das competências e habilidades relacionadas ao 'bom professor', a pesquisa de abordagem qualitativa, realizada pela autora em 2006 , com 50 professores dos cursos de licenciatura em Pedagogia, Biologia, Filosofia e Educação Física, de uma universidade pública e outra privada de Curitiba-PR, verificou que a qualidade de vida desses profissionais é comprometida em alguns aspectos que, consequentemente, interferem diretamente na prática pedagógica.

Os dados foram coletados mediante a aplicação de um questionário com questões abertas, fechadas e de múltipla escolha, cuja elaboração foi efetivada a partir do teor de algumas questões do questionário WHOQOL-10O, da Organização Mundial de Saúde (OMS), de literaturas pesquisadas ao longo do estudo e de experiências da autora em ações de educação para a qualidade de vida em diferentes instituições. Esse instrumento foi adequado à realidade do trabalho docente, oportunizando a expressão da subjetividade do professor.

Foram analisadas quatro categorias de fatores da qualidade de vida, indissociáveis: biológicos/físicos, psicológicos/afetivos, culturais/cognitivos e sociais/econômicos/laborais. Essa técnica possibilitou a atribuição de uma nota, por categoria, à qualidade de vida de cada sujeito, em uma escala de três intervalos: 
A qualidade de vida docente em cursos de licenciatura

a) classe ruim - composta pelas notas menores do que a média, menos um desvio padrão;

b) a classe boa - composta pelas notas maiores do que a média, mais um desvio padrão;

c) classe razoável - representa as notas entre as outras duas classes.

\section{RESULTADOS E DISCUSSÃO}

De maneira geral, a qualidade de vida dos professores que participaram da pesquisa foi classificada como razoável, representada pela nota 7,1 , obtida a partir da média das notas individuais, as quais, por sua vez, resultaram da média dos pontos atribuídos a cada questão.

Tabela 1 - Classificação das notas de qualidade de vida dos professores

\begin{tabular}{|c|c|c|c|}
\hline Notas & $>\mathbf{7 , 9}$ & $\mathbf{7 , 9}-\mathbf{6 , 3}$ & $<\mathbf{6 , 3}$ \\
\hline Classificação Geral & Boa & Razoável & Ruim \\
\hline Número de professores & 6 & 37 & 7 \\
\hline Percentual/grupo (50 profs.) & $12 \%$ & $74 \%$ & $14 \%$ \\
\hline
\end{tabular}

As categorias de fatores biológicos/físicos, psicológicos/afetivos e culturais/cognitivos foram classificadas como razoáveis, apontando os fatores que são mantidos pelos professores, mas que, pouco a pouco, são comprometidos pelo seu estilo de vida. Entretanto, curiosa e contraditoriamente, a categoria de fatores sociais/econômicos/ laborais foi a única classificada como boa (nota: 8,0).

Essa classificação tanto aponta o empenho dos professores frente ao seu trabalho - pois eles valorizam sua atividade profissional e vinculam seu trabalho ao provimento da família, compreendendo o trabalho, consciente e constantemente, como uma necessidade e um objetivo de vida - quanto explica a classificação razoável das outras três categorias, cujos fatores não são considerados, prioritariamente, na sua rotina diária. A valorização e dedicação diferenciada a esses fatores da qualidade de vida ocorrem de acordo com a significação atribuída a cada um deles pelo próprio sujeito. De acordo com Dejours (1992, p. 40), 
[...] ao mesmo tempo em que a atividade de trabalho comporta uma significação narcísica, ela pode suportar investimentos simbólicos e materiais destinados a um outro, isto é, ao objeto. A tarefa pode também veicular uma mensagem simbólica para alguém, ou contra alguém. A atividade do trabalho, pelos gestos que ela implica, pelos instrumentos que ela movimenta, pelo material tratado, pela atmosfera na qual ela opera, veicula um certo número de símbolos. A natureza e o encadeamento destes símbolos dependem, ao mesmo tempo, da vida interior do sujeito, isto é, do que ele põe, do que ele introduz de sentido simbólico no que o rodeia e no que ele faz.

Essa explicação também pode se aplicar à melhor classificação (nota: 7,2 ) da categoria de fatores culturais e cognitivos, dentre as classificadas como razoáveis, já que as atividades que representam esses fatores têm um significado muito peculiar ao profissional docente, bem como estão imediatamente relacionadas ao seu trabalho, precisando ser mantidas para subsidiar as atividades mais emergentes, exigentes e, conseqüentemente, desgastantes à qualidade de vida do professor. Dentre essas atividades desgastantes destaca-se a relação professor-aluno, quando é repleta de tensões que exigem o desdobramento de instâncias psicológicas e afetivas. Carlotto (2002) ressalta que, de acordo com estudos realizados com professores suíços, a relação professor-aluno é uma das principais causas de doenças psicossomáticas em docentes.

Com a preocupação voltada quase que exclusivamente para o trabalho e suas exigências, as atividades que contemplam os aspectos psicológicos, afetivos, biológicos e físicos passaram a ser consideradas como latentes e a serem defasadas, tornando esses aspectos cada vez mais carentes.

Nessa perspectiva, a categoria de fatores biológicos e físicos também foi classificada como razoável (nota: 6,7). A maioria dos professores deixou de praticar atividade física regularmente, sente-se muito estressada, sofre com nervosismo e ansiedade e não se alimenta com uma frequência apropriada durante o dia, passando a apresentar dificuldades de relaxamento e de descanso durante o sono.

Entretanto, esses resultados não dependem somente do fato de os professores se dedicarem mais ao trabalho, primando pela sua 
A qualidade de vida docente em cursos de licenciatura

capacidade cognitiva e pelo seu desenvolvimento cultural e, assim, deixando em défit aspectos da categoria de fatores biológicos/físicos e psicológicos/afetivos. Essa relação de compensação do professor que preza pelo âmbito do trabalho e coloca a sua vida particular à margem é também alimentada pela insatisfação financeira e desvalorização profissional, sentida mais fortemente pelos professores com maior comprometimento da sua qualidade de vida. Por outro lado, destaca-se que os professores, em sua grande maioria, valorizam o seu trabalho devido ao valor que atribuem ao seu produto social, ao mesmo tempo em que se valorizam na participação social.

É preciso notar que as condições do professor refletem a realidade do trabalho na sociedade capitalista, marcada por mediações, conquistas e derrotas da classe trabalhadora por melhores condições de trabalho e vida. Nesse sentido, o salário do professor é regulado pelo trabalho assalariado em geral pelo valor socialmente definido da força-de-trabalho. (ABREU; LANDINI, 2003, p. 04).

Sob essa lógica, a maioria dos professores incluiu nos seus objetivos de vida (essenciais à promoção da sua qualidade de vida), de forma geral, o trabalho, a saúde e o lazer, pois realmente sente que está sempre em débito com esses fatores. Já a família, o relacionamento intrapessoal, o relacionamento interpessoal e a educação/ formação não são apresentados como objetivos (projetos), com a mesma preocupação atribuída aos primeiros, já que são fatores explicitamente ligados e imediatos à rotina do professor. As atividades pedagógicas, que representam a maior parte do tempo diário do professor, são relativas à educação/formação e propriamente marcadas pelo relacionamento pessoal e inversamente proporcional ao pouco tempo que sobra para o docente dedicar-se a si mesmo. Essa limitação é evidenciada nas palavras de um professor:

"Nós, professores universitários, estamos com muitas atribuições e pouco tempo para dedicar a nós mesmos".

O resultado da categoria de fatores psicológicos e afetivos (nota: 6,7) demonstra e corrobora esse prejuízo, que é enfatizado pela prevalência de sentimentos negativos como nervosismo, ansiedade, irritação e mau humor, seguidos das dificuldades de relaxamento e de autovalorização, do sentimento de tristeza, angústia, vazio e solidão, 
e da baixa autoestima.

O professor acaba se perdendo de si mesmo; é diminuído em meio à imensidão de tarefas a cumprir em pouco tempo, que parecem se eternizar conforme se multiplicam enquanto o tempo se esvai. As tarefas que pareciam prioritárias vão passando para segundo plano quando, incessantemente, surgem outras imprevistas, que acabam suprimindo o professor e acomentendo o seu bem-estar, já que “(...) a subjetividade que se produz sobre estas condições é, ao mesmo tempo, marcada pela alienação, pelo medo e pela insegurança". (GENTILI, 2002, p. 71).

A forte relação entre trabalho, saúde e educação se dá pela complexidade da qualidade de vida. $\mathrm{O}$ acometimento de um desses fatores prejudica todos os demais, colocando-os em um círculo vicioso de mal-estar, ao passo que a incidência frequente desse sentimento pode resultar em diversos tipos de doença, dentre as quais uma das mais recorrentes é a síndrome de Burnout. Conhecida como um estresse ocupacional, essa síndrome é muito comum entre os profissionais que trabalham com seres humanos, mantendo com eles uma relação de atenção direta, contínua e altamente emocional. (MASLACH; LEITER, 1999). As principais características da síndrome de Burnout são:

a exaustão profissional, onde os mesmos sentem que chegaram ao limite do que poderiam dar de si no trabalho; a despersonalização, em que as relações estabelecidas com o outro são frias, distantes e impessoais, muitas vezes agressivas, e a falta de envolvimento pessoal no trabalho, em que o trabalhador perde habilidade para realizar o trabalho. (CODO, 2006, p. 237).

Para o surgimento da síndrome citada, Lacaz (2010, p. 56) destaca as seguintes situações:

a desvalorização da profissão docente, quando se atua demais em tarefas burocráticas; a falta de autonomia e de participação nas definições das políticas de ensino; a inadequação salarial; a falta de oportunidade de promoções; o isolamento social e a baixa solidariedade; o baixo envolvimento associativosindical; as precárias e inadequadas condições físicas e materiais; o relacionamento com familiares de alunos pouco implicados no processo de ensinoaprendizagem, e a cada vez maior cobrança da sociedade quanto aos resultados do trabalho docente. 
A qualidade de vida docente em cursos de licenciatura

Em face dessas adversidades, uma pesquisa sobre o estresse ocupacional docente, realizada em 2002 pela Confederação Nacional dos Trabalhadores em Educação (CNTE), em dez estados brasileiros, salienta que:

Os docentes estão permanentemente sujeitos a deteriorização intensa da saúde, organismos internacionais reconhecem o estresse como enfermidade profissional que na opinião da OIT, não é um fenômeno isolado, mas um risco operacional significativo da profissão. (VIEIRA, 2003, p. 27).

A síndrome de Burnout, enquanto um resultado da má relação entre a pessoa e a realidade da sua prática profissional, repercute tanto na saúde do indivíduo quanto na própria ação docente.

[...] o professor pode apresentar prejuízos em seu planejamento de aula, tornando-se este menos freqüente e cuidadoso. Apresenta perda de entusiasmo e criatividade, sentindo menos simpatia pelos alunos e menos otimismo quanto à avaliação de seu futuro.

(CARLOTTO, 2002, p. 24).

Nesse contexto, é problemático que, para a maioria dos professores, a melhoria da sua qualidade de vida esteja relacionada a realizações no trabalho, à saúde e ao lazer, posicionamento esse que decorre da visão da qualidade de vida como um objetivo distante da sua realidade e/ou difícil de ser alcançado. Isso ainda contrasta com o fato de as aptidões, habilidades e competências para a conquista dos seus objetivos de vida não terem sido consideradas como necessárias diretamente à sua qualidade de vida. Mas, como é possível alcançar um objetivo sem saber como agir, ou realizar algo que nem se sabe que quer realizar?

Os professores têm como objetivo de vida o trabalho (apesar de esse objetivo estar muitas vezes relacionado à constante sensação de dívida) e, coerentemente, desenvolvem as aptidões culturais e cognitivas necessárias a realização desse propósito. Todavia, ao se tratar dos outros aspectos da sua vida, que geralmente dizem respeito ao seu bem-estar particular (fatores físicos/biológicos e psicológicos/ afetivos), não só não os colocam claramente como objetivos de vida, como também não percebem as aptidões necessárias à sua realização. 
Compreendem o trabalho como o 'existente absoluto' e, ao mesmo tempo, colocam-se à margem de si mesmos, demonstrando suscetibilidade a doenças psicossomáticas, como a síndrome de Burnout. Zuin (1999, p. 57) atenta para o perigo de se absolutizar ainda uma tendência de adaptação ao existente, que é a "[...] aversão a qualquer possibilidade de uma atitude de distanciamento em relação ao mundo fenomênico que poderia encetar reflexão e questionamento da barbárie".

Esse problema é ainda salientado pelo fato de os professores não expressarem objetivos relacionados ao meio ambiente e ao próprio contexto (meio entorno), provavelmente devido à sua acentuada rotina, que não lhes propicia o tempo necessário para a percepção, reflexão e integração com o meio à sua volta, dificultando o aproveitamento de recursos disponíveis que poderiam favorecer a sua qualidade de vida e subsidiar a própria prática profissional. Essa relação de fatores demonstra que o trabalho docente não foge às características de um trabalho alienado, que acaba gerando estranheza ao trabalhador, tanto em relação à totalidade do processo produtivo quanto ao produto final do seu trabalho. (MARX, 1993).

Em comum, esses resultados evidenciam o excedente tempo e a sobrecarga de trabalho do professor, em detrimento do lazer, do relacionamento intrapessoal para o autoconhecimento, o autodesenvolvimento e a autoestima, e de melhores possibilidades de reflexão e dedicação a atividades que promovam a sua saúde.

A concepção de qualidade de vida desses professores corrobora essa análise, uma vez que os seus conceitos apresentaram-se como expressão da subjetividade individual e subsídio às atividades humanas, estando o trabalho, o relacionamento intra e interpessoal e o lazer frequentemente presentes. Porém, esses conceitos também apontam uma tendência de reprodução, enquanto equivalentes ao conceito de saúde da OMS, da mesma forma que são abordados pela mídia, configurando-se como senso comum. Já a família, o contexto e os valores são dimensões presentes em apenas alguns dos conceitos; o meio ambiente e as aptidões humanas são praticamente desconsiderados, e a educação e formação docente nem aparecem. Os fatores qualidade de vida e trabalho, intimamente inbricados, são vistos como polos opostos.

Sobre a forma antinômica do trabalho, Marx lembra que: 
A qualidade de vida docente em cursos de licenciatura

[...] frente ao capital, que é trabalho objetivo, o trabalho nãoobjetivado apresenta-se de duas maneiras: negativamente como não-matéria-prima, não instrumento, não-produto, isto é, como miséria absoluta; positivamente, como existência do trabalho não como objeto, mas como atividade e possibilidade universal de riqueza. É aqui, portanto, que trabalho alienado e atividade vital humana, trabalho e manifestação de si, retornam numa oposição de positivo e negativo rigorosamente assinalada. (apud MANACORDA, 1991, p. 51-52).

Esses resultados apontam para um distanciamento entre o professor, sujeito concreto, e a sua qualidade de vida, pois ele tende a projetá-la para tão longe da sua rotina que, na maioria das vezes, acaba tornando-a inatingível. Além disso, suas possibilidades de mudança estão nas aptidões desconsideradas nos seus objetivos. O mesmo acontece com a educação/formação, que, com um viés de continuidade (Educação Continuada) vivenciada pelo professor na posição de educando, poderia viabilizar-lhe o desenvolvimento dessas aptidões, já que privilegia atividades de reflexão. Tais dificuldades indicam mais uma incongruência entre teoria e prática, entre o que os professores entendem como importante e aquilo que lhes é imprescindível para realizar o que almejam: sua própria qualidade de vida.

Nesse sentido, a comparação entre as concepções de qualidade de vida dos professores que apresentaram as cinco melhores e as cinco piores classificações evidenciou seus valores, suas aspirações e suas principais atividades cotidianas. Contudo, possibilitou registrar uma diferença significativa com relação ao hábito de reflexão dos professores sobre a qualidade de vida. Enquanto os professores com menores notas reduzem essa reflexão a situações de conflito ou problemas, os com melhor pontuação costumam refletir diariamente, reconstruindo sua qualidade de vida, continuamente.

Assim, os docentes com sua qualidade de vida comprometida apresentam dificuldades de modificação desse quadro, na medida em que tendem a refletir movidos pela necessidade e não por uma decisão pessoal consciente, e a repetir as mesmas atividades habituais, que são insuficientes à melhoria da sua qualidade de vida, considerandose que essa mudança requer uma série de fatores que constituem as categorias mais comprometidas. Essa "aparente dicotomia" desequilibrada entre vida pessoal e profissional desdobra-se na contramão do bem-estar docente e atinge a educação. 
Efetivamente, diante do avanço do mal-estar docente, os professores colocam em jogo diversos mecanismos de defesa, como são os esquemas de inibição ou o absenteísmo trabalhista, que apresentam o aspecto negativo de rebaixar a qualidade da educação, mas que serve para aliviar a tensão a que o professor está submetido. (ESTEVE, 1999, p. 79).

De um lado, essa “tensão situa-se no risco do determinismo economicista e das estruturas e, de outro, no voluntarismo subjetivista, que automatiza o sujeito" (GENTILI, 2002, p. 63), privando-o da liberdade, da escolha e do desenvolvimento humano.

\section{CONSIDERAÇÕES FINAIS}

A prática pedagógica e a qualidade de vida do professor apresentam uma forte relação de reciprocidade. A docência depende de uma diversidade de habilidades que se compõem e dispõem a partir da integridade humana. Para que o educador possa selecionar essas habilidades, aprimorá-las, colocá-las em prática e refletir sobre essa prática, é preciso que ele saiba perceber, conhecer, relacionar e avaliar a si mesmo, considerando-se em seu contexto biológico, psicológico, social, cultural, espiritual, ecológico como indivíduo, pessoa, sujeito histórico e profissional. Porém, esse contexto é comprometido e comprometedor na realidade do trabalho docente.

Assim, o estudo revela a importância da práxis, que, de acordo com Freire (1987, p. 92), "é fonte de conhecimento reflexivo e de criação"; é o meio de se tomar consciência da realidade e de, então, recuperar a valorização e a vivência da liberdade, da escolha e do desenvolvimento humano, essenciais à promoção da qualidade de vida, a qual requer dinamismo de pensamento e ação. É necessário dirigir a reflexão à reconstrução da concepção sobre o assunto, de forma que se favoreça o desenvolvimento de objetivos capazes de gerar a mudança de atitudes e ações, e estas, modificadas, tornem-se hábitos saudáveis para uma melhor qualidade de vida. Como afirma Freire (1987, p. 91), "no momento em que a percepção crítica se instaura, na ação mesma, se desenvolve um clima de esperança e confiança que leva os homens a se empenharem na superação das 'situações-limites"'.

Entretanto, o contexto histórico e sociocultural em que se inserem os resultados do estudo indica que essa mudança não compete apenas 
ao professor. Muito pelo contrário: “[...] a questão central é política - liberação de tempo livre, pela diminuição da jornada de trabalho e distribuição, mediante a esfera pública sob o controle democrático da sociedade, da riqueza produzida". (GENTILI, 2002, p. 71).

As instituições de ensino superior precisam atrelar aos seus objetivos "teóricos" a realidade "prática" de quem realiza a educação diretamente na relação com o educando, favorecendo também a superação prática de uma outra dicotomia marcada pelo distânciamento entre universidade e sociedade. Nesse sentido, Pimenta e Anastasiou (2002, p. 89) afirmam que:

valorizar o trabalho docente significa dotar os professores de perspectivas de análise, que os ajudem a compreender os contextos históricos, sociais, culturais, organizacionais nos quais se dá a atividade docente; significa também rever e modificar a precariedade da carreira docente nas diferentes instituições de ensino superior.

Com efeito, o alcance desse cuidado pode ser expandido no caso de beneficiar, especialmente, os professores dos cursos de licenciaturas, que demonstraram a necessidade de melhor qualidade de vida implicada na sua prática pedagógica e que são responsáveis pela formação de novos professores, o que é explanado por um dos docentes, ao afirmar que "o profissional feliz e motivado é muito mais produtivo! E a atividade do professor é diretamente refletida no aluno."

Porém, tais ações não podem ser pontuais e paliativas, e nem explorar o tempo livre do professor, realizando-se na esfera do sobretrabalho e na ótica da lucratividade. Devem priorizar um momento especial durante o próprio tempo de trabalho e sob a real vontade de participação dos professores. A melhoria da qualidade de vida dos professores de licenciaturas pode ser estimulada por trabalhos contínuos de educação, mobilização e intervenção, planejados e realizados pelas Instituições de Ensino Superior, a partir da conscientização organizacional, e direcionados à construção de conceitos de qualidade de vida pelos professores e à incorporação de posturas reflexivas que possibilitem a transformação de estilos de vida prejudicados e prejudiciais.

As instituições de ensino podem contribuir de muitas maneiras para a melhoria de vida dos docentes que nelas exercem suas funções, como mostram as transcrições apresentadas a seguir: 
"A conscientização traria maior preocupação com a qualidade de vida".

"Considerando o tempo que passo na instituição, seria importante se ela oferecesse algo mais que trabalho."

"Acredito que seria uma maneira da IES pensar e valorizar os professores".

"Demonstraria a importância do servidor e que a instituição estaria preocupada com a nossa situação. Incentivaria a promoção da saúde e do bem estar".

"As pessoas precisam de boa qualidade de vida para ser bons profissionais".

"Respeito ao profissional."

“Informação e prevenção."

"Preservação de seus funcionários."

Para que as necessárias transformações ou mudanças sejam concretizadas, o poder público também precisa adequar seus objetivos a esse propósito e colocá-los em ação. De acordo com Lacaz (2010, p. 57), "no campo político, é preciso esclarecer a sociedade quanto ao caráter nefasto do processo em curso e organizar a luta necessária para reverter o quadro que se apresenta".

Nesse sentido, entende-se que o ANDES - Sindicato Nacional, ao empreender a discussão da temática, como aconteceu no Encontro Nacional sobre Saúde do Trabalhador: "Educação Submissa à Lógica do Capital: da precarização do trabalho docente à Saúdedo Professor: os desafios atuais", realizado em 31/07 e 01/08/2009 em São Paulo, inaugura uma fase importante na luta pela melhoria das condições e processos de trabalho e em defesa da saúde docente. Desdobramentos deste Encontro têm acontecido em vários estados do Brasil, mobilizando Associações Docentes das Instituições de Ensino Superior, tanto Federais quanto Estaduais, trazendo uma perspectiva estratégica de enfrentamento orgânico desta perversa 
A qualidade de vida docente em cursos de licenciatura

realidade, hoje vivida, no que se refere ao trabalho na carreira docente, dentro das instituições públicas de ensino superior. (LACAZ, 2010, p. 57).

Na perspectiva de socializar o conhecimento sobre a realidade hoje vivida e conquistar melhorias, especialmente no que concerne à saúde do trabalhador, levando as medidas previstas à instância do Governo Federal, o Departamento Intersindical de Estudos e Pesquisas em Saúde e dos Ambientes de Trabalho (Diesat), fundado em 1980 por vários sindicatos e federações de trabalhadores de todo o Brasil, assessora o movimento sindical em pesquisas, formação e capacitação de quadros sindicais, e disponibiliza informativos de circulação pública sobre esse quadro. (LACAZ, 2010).

Todavia, essa discussão ainda não ganhou o espaço necessário e a devida atenção no âmbito federal. As medidas tomadas ainda não beneficiam a qualidade de vida docente, sob um viés preventivo, apesar de discussões em encontros próprios da área da Educação já terem apontado necessidades emergentes das condições de trabalho e saúde dos profissionais envolvidos com o ensino brasileiro. Foi o que aconteceu na Conferência Nacional de Educação (CONAE), realizada pelo Ministério da Educação (MEC) em Brasília, no período de 28 de março a $1^{\circ}$ de abril de 2010 , com base em discussões desenvolvidas por todos os municípios brasileiros ao longo do ano de 2009. Realizada recentemente, essa conferência propôs mudanças já para o ano de 2011, cujo acompanhamento é de extrema importância pela população, considerando que “o homem é essencialmente 'político', já que a atividade para transformar e dirigir conscientemente os homens realiza a sua humanidade, a sua natureza humana". (GRAMSCI, 1989, p. 47).

Em suma, as instituições organizacionais realmente preocupadas com a qualidade de vida dos professores requerem a transgressão da filosofia de indústria cultural para uma filosofia complexa, que considere os "conhecimentos pertinentes ao mundo". (MORIN, 2003). Integrando-se o discurso social, que expressa a realidade vivida, ao propósito da melhor qualidade de vida, reivindicada no próprio contexto do trabalho docente, torna-se possível realizar as necessárias transgressões e mudanças. Para orientá-las, os estudos realizados sob essa perspectiva são essenciais, pois compartilham da visão de Gentili (2002, p. 70), ao entender que “a relação entre 
estrutura, determinações e sujeito, em sua tensão e mútua imbricação dialética deve ser considerada como fio condutor dos nossos objetivos específicos sobre a pesquisa trabalho-educação".

\section{REFERÊNCIAS}

ABREU, C. B. M.; LANDINI, S. R. Trabalho docente: a dinâmica entre formação, profissionalização e proletarização na constituição da identidade. Revista Diálogo Educacional, v. 4, n. 8, p. 33-44, jan./abr., 2003.

ANTUNES, R. Adeus ao trabalho? Ensaios sobre a metamorfose e a centralidade do mundo do trabalho. São Paulo: Cortez, 2006.

ASSUNÇÃO, A. A. Saúde e condições de trabalho nas escolas públicas. In: OLIVEIRA, D. A. (Org.). Reformas educacionais na América Latina e os trabalhadores docentes. Belo Horizonte: Autêntica, 2003. p. 87-102.

BERTUOL, F. P. Qualidade de vida de professores de licenciaturas. Curitiba, 2006. 117 f. Dissertação (Mestrado em Educação), Centro de Teologia e Ciências Humanas, Pontifícia Universidade Católica do Paraná.

BORDIEU, P. A reprodução: elementos para uma teoria do sistema de ensino. Rio de Janeiro: Editora Francisco Alves, 1982.

CAMBI, F. História pedagógica. São Paulo: Editora Unesp, 1999.

CARLOTTO, M. S. A síndrome de Burnout e o trabalho docente. Psicologia em Estudo, Maringá, v. 7, n. 1, p. 21-29, jan./jun., 2002.

CHIAVENATO, I. Introdução à teoria geral da administração. 4. ed. São Paulo: Makron, 1993.

CODO, W. (Org.). Educação: carinho e trabalho. Petrópolis: Vozes, 2006.

CONAE - MINISTÉRIO DA EDUCAÇÃO. Disponível em: < http://conae.mec. gov.br/images/stories/pdf/noticias/mudancas_educacao_implantadas.pdf $>$. Acesso em: 09 abr. 2010.

CUNHA, M. I. O bom professor e sua prática. 10. ed. Campinas: Papirus, 1989.

DÉJOURS, C. A loucura do trabalho: estudo de psicopatologia do trabalho. 4. ed. São Paulo, Cortez, 1989.

DEJOURS, C. Uma nova visão do sofrimento humano nas organizações. In: CHANLAT, J. F. (Ed.). O indivíduo na organização: dimensões esquecidas. São Paulo: Atlas, 1992. p. 150-173. 
A qualidade de vida docente em cursos de licenciatura

ENGUITA, M. F. A face oculta da escola: educação e trabalho no capitalismo. Porto Alegre: Artes Médicas, 1989.

ESTEVE, J. M. O mal-estar docente: a sala de aula e a saúde dos professores. São Paulo: EDUSC, 1999.

FERRARI, I. (Org.). História do trabalho, do direito do trabalho e da justiça do trabalho. São Paulo: LTr, 1998.

FLECK, M. P. A. et al. Aplicação da versão em português do instrumento de avaliação da OMS (WHOQOL-100). Revista de Saúde Pública, São Paulo, v. 33, n. 2, p.198-205, abr., 1999.

FREIRE, P. Pedagogia do oprimido. 17. ed. Rio de Janeiro: Paz e Terra, 1987.

GENTILI, P. Três teses sobre a relação trabalho e educação em tempos neoliberais. In: LOMBARDI, J. C.; SAVIANI, D.; SANFELICI, J. L. (Orgs.). Transformações do capitalismo, no mundo do trabalho e da educação. Campinas, SP: Autores Associados, HISTEDBR, 2002. p. 45-60.

GIROUX, H. A. Os professores como intelectuais: rumo a uma pedagogia crítica de aprendizagem. Porto Alegre: Artes Médicas, 1997.

GRAMSCI, A. Concepção dialética da história. 8. ed. Rio de Janeiro: Civilização Brasileira, 1989.

GUATTARI, F. Caosmose um novo paradigma estético. Rio de Janeiro: Editora 34, 1993.

LACAZ, F. A. de C. Capitalismo organizacional e trabalho: a saúde do docente. Universidade e Sociedade, n. 45, p. 51-60, jan. 2010.

LANDINI, S. R. Professor, trabalho e saúde: as políticas educacionais, a materialidade histórica e as conseqüências para a saúde do trabalhador-professor. Colloquium Humanarum, v. 4, n.1, p. 08-21, jun. 2007.

LIMONGI-FRANÇA, A. C. Qualidade de vida no trabalho: conceitos e práticas nas empresas da sociedade pós-industrial. São Paulo, Editora Atlas, 2004.

MASLACH, C.; LEITER, M. P. (1999). Take this job and love it. Psychology Today, n. 32, p. 50-57, 1999.

MANACORDA, M. A. Marx e a pedagogia moderna. São Paulo: Cortez Autores Associados, 1991.

MARX, K. Os manuscritos econômicos e filosóficos. Vol. 22. Textos filosóficos. Lisboa, Portugal: Edições 7O, 1993.

MELLO, G. N. de (Org.). Escola nova, tecnicismo e educação contemporânea. São Paulo: Loyola, 1982. Disponível em <http://www.uepg.br/olhardeprofessor> 
MOREIRA, W. W. Qualidade de vida: complexidade e educação. Campinas, SP: Papirus, 2001.

MORIN, E. Os sete saberes necessários à educação do futuro. 8. ed. São Paulo: Cortez; Brasília, DF: UNESCO, 2003.

PIMENTA, S. G.; ANASTASIOU, L. G. C. Docência no ensino superior. São Paulo: Cortez, 2002.

SAVIANI, D. Transformações do capitalismo, do mundo do trabalho e da educação. In: LOMBARDI, J. C.; SAVIANI, D.; SANFELICI, J. L. (Orgs.). Transformações do capitalismo, no mundo do trabalho e da educação. Campinas, SP: Autores Associados, HISTEDBR, 2002. p. 13-26.

TEIXEIRA, A. Ensino superior no Brasil: análise e interpretação de sua evolução até 1969. Rio de Janeiro: Editora da Fundação Getúlio Vargas, 1989.

The WHOQOL Group. The World Health Organization quality of life assessment (WHOQOL): position paper from the World Health Organization. Social Science and Medicine, n. 10, p. 1403-1409, 1995.

VIEIRA, J. D. Identidade expropriada: retrato do educador brasileiro. Brasília: CNTE, 2003.

ZUIN, A. A. S. Indústria cultural e educação: o novo canto da sereia. Campinas, SP: Autores Associados, 1999.

Enviado em: 04/09

Aceito em: 11/09 